\title{
Perancangan dan Implementasi Aplikasi Panduan Pariwisata Mobile di Kabupaten Semarang menggunakan LWUIT pada J2ME
}

\author{
${ }^{1)}$ Eko Diliyanto Lewi, ${ }^{2)}$ Rini Kartika Hudiono, ${ }^{3)}$ Ramos Somya
}

\author{
Fakultas Teknologi Informasi \\ Universitas Kristen Satya Wacana \\ Jl. Diponegoro 52-60, Salatiga 50711, Indonesia \\ Email: ${ }^{1)}$ ekodili@y mail.com, ${ }^{2)}$ rin ihudiono@gmail.com, ${ }^{3)}$ ramos.6005@g mail.com
}

\begin{abstract}
LWUIT is a library to UI's widget that was designed to a device with limited capacity, like mobile phone that can give an interesting menu and help developer to develop its components. In this research, LWUIT was implemented on a J2ME mobile tourism guide application in Semarang Regency that could be used to show some information about tourism objects attractively. So, users would be attracted to have a vacation in Semarang Regency after making use of it. This application gave information mostly needed by tourists like something to see, something to do, and something to buy in tourist objects located in Semarang Regency. In addition, It gave information in map model that could help users to understand tourism object in Semarang Regency more clearly. Hopefully, It benefits to Dinas Pemuda, Olahraga, Kebudayaan, dan Pariwisata in Semarang Regency on tourism objects promotion.
\end{abstract}

Keywords: J2ME, LWUIT, mobile information

\begin{abstract}
Abstrak
LWUIT merupakan sebuah library untuk widget UI yang di desain untuk device dengan kapasitas terbatas seperti mobile phone yang dapat menyajikan aplikasi dengan tampilan lebih menarik serta memudahkan developer dalam melakukan develope komponen. Pada penelitian ini LWUIT diimplementasikan pada sebuah aplikasi panduan pariwisata mobile J2ME di kabupaten Semarang yang dapat digunakan untuk menampilkan informasi mengenai objek wisata dengan lebih menarik. Hal ini memberikan manfaat bagi Dinas Pemuda, Olahraga, Kebudayaan, dan Pariwisata Kabupaten Semarang sebagai media promosi objek wisata kepada masyarakat luas agar wisatawan tertarik untuk melakukan perjalanan wisata di kabupaten Semarang setelah menjalankan aplikasi tersebut. Aplikasi ini memberikan informasi berupa apa saja yang bisa dilihat, dilakukan, dan dibeli oleh pengguna pada objek wisata yang ada di kabupaten Semarang. Aplikasi ini juga menyediakan informasi dalam bentuk peta yang dapat membantu pengguna mengetahui lebih jelas lokasi objek wisata di kabupaten Semarang.
\end{abstract}

Kata Kunci : LWUIT, J2ME, informasi mobile

\section{Pendahuluan}

Kabupaten Semarang merupakan sebuah kabupaten di Provinsi Jawa Tengah dengan ibukotanya adalah kota Ungaran dengan berbagai obyek wisata yang terus dipromosikan oleh pemerintah. Hal-hal tersebut mendorong dibangunnya sebuah dukungan teknologi pada perangkat komunikasi mobile atau handphone dengan ditanamkannya sebuah aplikasi yang mampu menyediakan informasi secara khusus mengenai objek wisata yang ada di kabupaten Semarang dengan tambahan maps atau peta pada setiap objek wisata yang bersangkutan serta disajikan dengan user interface atau tampilan yang menarik karena penerapan LWUIT pada J2ME sehingga mampu menarik perhatian user untuk segera menjalankan aplikasi tersebut. Penerapan dilakukan pada aplikasi mobile di dalam perangkat komunikasi atau handphone yang memiliki sistem operasi java atau symbian.

Tujuan dari penelitian ini adalah "Merancang aplikasi panduan pariwisata mobile di Kabupaten Semarang menggunakan LWUIT pada J2ME". Adapun manfaat yang diharapkan dengan dirancangnya aplikasi panduan pariwisata mobile ini adalah dapat menyajikan informasi yang ada melalui media lain yaitu pada perangkat mobile atau handphone guna membantu dan menarik minat calon wisatawan atau wisatawan dalam mengunjungi dan memperoleh informasi mengenai objek wisata di kabupaten Semarang serta membantu pihak Dinas Pemuda, Olahraga, Kebudayaan, dan Pariwisata Kabupaten Semarang dalam melakukan promosi objek wisata di 
kabupaten Semarang yang ada dengan lebih efektif dan efisien kepada masyarakat luas. Sedangkan secara teknis penggunaan aplikasi ini mampu mempersingkat langkah dalam mendapatkan informasi mengenai objek wisata di Kabupaten Semarang dibandingkan akses informasi pada halaman web yang disediakan oleh pihak Dinas Pemuda, Olahraga, Kebudayaan, dan Pariwisata Kabupaten Semarang.

\section{Tinjauan Pustaka}

Penerapan LWUIT dan pembuatan aplikasi panduan pariwisata mobile sudah banyak dilakukan dalam berbagai penelitian, salah satu diantaranya adalah penelitian yang berjudul Game Ilmu Pengetahuan Untuk Usia Tiga Sampai Tujuh Tahun Berbasis J2ME [2] yang menyatakan bahwa LWUIT menghindari lowest common denominator yakni mengimplementasikan beberapa fitur pada platform low-end dan membawa hasil yang lebih baik pada plaform high-end. Dimana aplikasi ini membahas mengenai aplikasi yang dapat membantu anak usia tiga sampai tujuh tahun untuk belajar ilmu pengetahuan melalui game pada perangkat mobile berbasis J2ME menggunakan framework LWUIT. Sedangkan penelitian tentang pembuatan aplikasi panduan pariwisata berbasis mobile yaitu Aplikasi Bergerak (Mobile Application) Pemandu Wisata Wilayah Malang Raya Berbasis J2ME [3] Aplikasi ini membahas mengenai aplikasi yang dapat membantu wisatawan untuk mengetahui informasi objek wisata secara mobile akan tetapi data yang diakses tidak bersifat dinamis, sehingga jika terjadi perubahan data maka aplikasi yang sudah jadi dibongkar kembali untuk dilakukan perubahan. Pada aplikasi ini menggunakan java 2 platform micro edition (J2ME) sebagai modul untuk membuat interface dan fungsi. Class canvas digunakan untuk memanggil objek gambar sebagai peta, sedangkan untuk aplikasi database menggunakan Record Management System yang mendukung aplikasi J2ME.

J2ME

Java 2 Micro Edition atau biasa yang disebut J2ME adalah lingkungan pengembangan yang didesain untuk meletakkan perangkat lunak Java pada barang elektronik beserta perangkat pendukungnya [4]. Pada J2ME, jika perangkat lunak berfungsi baik pada sebuah perangkat maka belum tentu juga berfungsi baik pada perangkat yang lainnya. J2ME membawa Java ke dunia informasi, komunikasi dan perangkat komputasi selain perangkat komputer dekstop yang biasanya lebih kecil dibandingkan perangkat komputer dekstop. J2ME biasa digunakan pada telepon seluler, pager, personal digital assistants (PDA) dan sejenisnya.

Komponen-komponen J2ME terdiri dari Java Virtual Machine (JVM) yang digunakan

untuk menjalankan aplikasi Java pada emulator atau handheld device, Java API (Aplication Programming Interface) dan tools lain untuk pengembangan aplikasi Java semacam emulator Java Phone , emulator Motorolla dari J2ME wireless toolkit.

\section{LWUIT}

Lightweight User Interface Toolkit (LWUIT) adalah lightweight widget library dari SUN Microsystem yang terinspirasi oleh swing namun di desain untuk device dengan kapastitas terbatas seperti mobile phone dan PDA. LWUIT mendukung kemampuan pluggable theme, hirarki komponen dan kontainer dan abstraksi di bawah GUI toolkit [5]. Interface internal dan kelas abstrak menyediakan abstraction dari interface dan API pada profile sehingga memudahkan portability dan migrasi untuk device dan profile di masa mendatang. LWUIT menghindari lowest common denominator yakni mengimplementasikan beberapa fitur pada platform low-end dan membawa hasil yang lebih baik pada plaform high-end.

LWUIT merupakan sebuah library untuk widget UI dan tidak mengatur tentang bagaimana sistem pada device seperti networking atau storage. Hal yang berkaitan dengan sistem sudah diatur oleh Java ME profile sebab LWUIT pada dasarnya adalah sebuah UI framework yang menawarkan antar muka yang lebih baik, teratur dan mudah untuk diimplementasikan oleh developer. Untuk membuat menjadi portable, LWUIT mengimplementasikan layer tipis di atas native system dari kanvas dan menyediakan sebuah widget abstraction. Abstraction tersebut digunakan dengan memanfaatkan kelas-kelas yang ada di dalam sistem seperti Graphic, Image, dan Font.

Gambar 1 adalah menunjukkan hirarki atau Struktur Komponen pada LWUIT. 


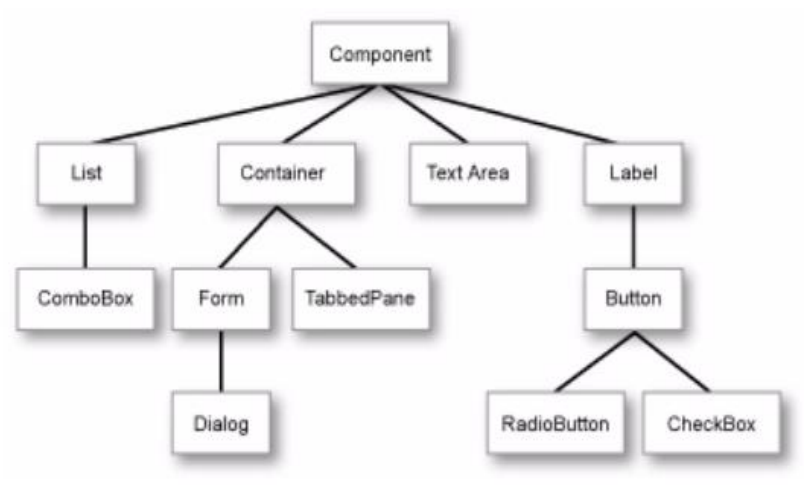

Gambar 1 Struktur Komponen LW UIT [5]

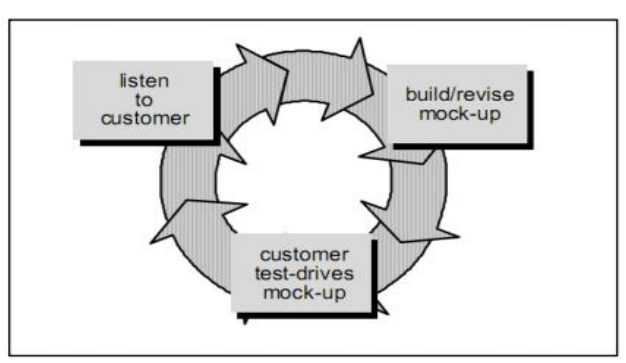

Gambar 2 Tahapan dalam Model Prototyping [8]

Kelebihan yang ditawarkan oleh LWUIT selain menyediakan desain antarmuka yang menarik adalah komponen pada LWUIT lebih membuka akses untuk membuat komponen custom. Misalnya, pada LWUIT terdapat method setBgColor atau setFgColor dimana semua hal ini jika dilakukan di J2ME harus meng-override method canvasnya. LWUIT memberikan lebih banyak model kontainer, sehingga pengembang aplikasi bisa lebih mudah meletakkan komponen di tempat yang diinginkan. LWUIT juga memiliki mekanisme dalam scaling image yang low memory cost, mekanisme ini digunakan baik pada saat penggambaran image untuk background aplikasi, background button, ataupun background komponen lainnya. Selain scaling ada juga mekanisme untuk repeat image (repeat horizontal, repeat vertical, ataupun repeat both). Sehingga tidak perlu lagi membuat banyak image untuk masing-masing resolusi layar. Selain itu dengan adanya pluggable themes semua styling di aplikasi yang menggunakan LWUIT bisa diseragamkan hanya dengan load themes tersebut di aplikasinya [6].

\section{Pariwisata}

Daya tarik wisata (atraksi wisata) yaitu hal-hal yang terdapat di obyek-obyek wisata dan dapat menarik pengunjung untuk datang ke tempat tersebut untuk berwisata. Untuk dapat menarik wisatawan bahwa daerah tujuan wisata (DTW) selain harus memiliki obyek dan atraksi wisata harus mempunyai tiga (3) syarat untuk meningkatkan daya tariknya, yaitu :

- Sesuatu yang dapat dilihat (something to see)

- Sesuatu yang dapat dikerjakan (something to do)

- Sesuatu yang dapat dibeli (something to buy)

Ketiga syarat tersebut merupakan unsur-unsur untuk mempublikasikan pariwisata, karena seorang wisatawan yang datang ke suatu daerah tujuan wisata memiliki tujuan untuk memperoleh manfaat atau keuntungan (benefit) dan kepuasan (satisfaction).

Disamping itu, manfaat internet untuk pariwisata pun telah menjadi salah satu solusi yang ditawarkan untuk mempermudah kinerja pengembangan pariwisata di Indonesia. Hal ini memungkinkan penyebaran informasi mengenai pengembangan pariwisata bisa diakses kapan, dimana, serta oleh siapa saja.

\section{Metode Penelitian}

Bagian ini terdiri atas: a) tempat dan waktu penelitian, serta b) bahan dan cara kerja (yang meliputi: prosedur, teknik, rancangan percobaan, dan analis is data). Metode pengembangan sistem yang digunakan pada penelitian ini adalah metode Prototyping. Prototyping adalah proses yang digunakan untuk membantu pengembangan perangkat lunak dalam membentuk model dari perangkat lunak yang harus dibuat [8]. Metode ini dilakukan secara bertahap, yaitu dengan mengembangkan suatu prototype yang sederhana terlebih dahulu baru kemudian dikembangkan dari waktu ke waktu sampai perangkat lunak selesai dikembangkan. Prototype merupakan bentuk dasar atau model awal dari suatu sistem atau subsistem. Tahap-tahap dalam metode Prototype ditunjukkan pada Gambar 2. 
Proses atau tahapan dalam penyelesaian masalah pada prototyping model yaitu dimulai dengan mengumpulkan data yang dilakukan melalui metode wawancara dengan pihak Dinas Pemuda, Olahraga, Kebudayaan, dan Pariwisata Kabupaten Semarang dengan mencari tahu kebutuhan user yang nantinya akan menggunakan aplikasi tersebut, serta tujuan umum dan gambaran bagian-bagian yang akan dibutuhkan berikutnya. Tahapan kedua yaitu membangun sistem berdasarkan hasil dari tahapan sebelumnya. Pada tahap ini dilakukan desain sistem dan antarmuka. Tahap ketigapun melakukan pengujian terhadap kondisi sistem yang dibangun apakah telah berjalan sesuai dengan rancangan sistem yang telah ditentukan sebelumnya, dilakukan oleh masyarakat dan perwakilan pihak Pemerintah.

\section{Perancangan Sistem}

Dalam tahap ini dilakukan desain sistem dan perangkat lunak untuk menggambarkan prosedur dan proses kerja dari aplikasi tersebut. Proses bisnis yang terjadi adalah user melakukan proses instalasi aplikasi pada perangkat mobile masing-masing, user dapat mulai menjalankan aplikasinya. Pertama akan muncul Splash Screen yang menandakan bahwa aplikasi tersebut sudah siap digunakan oleh user kemudian user dapat masuk ke halaman utama yang terdapat menu Informasi Objek Wisata, Peta (Objek Wisata), Fast Respon, Bantuan, dan Profil. Proses bisnis aplikasi user ditunjukkan pada Gambar 3.

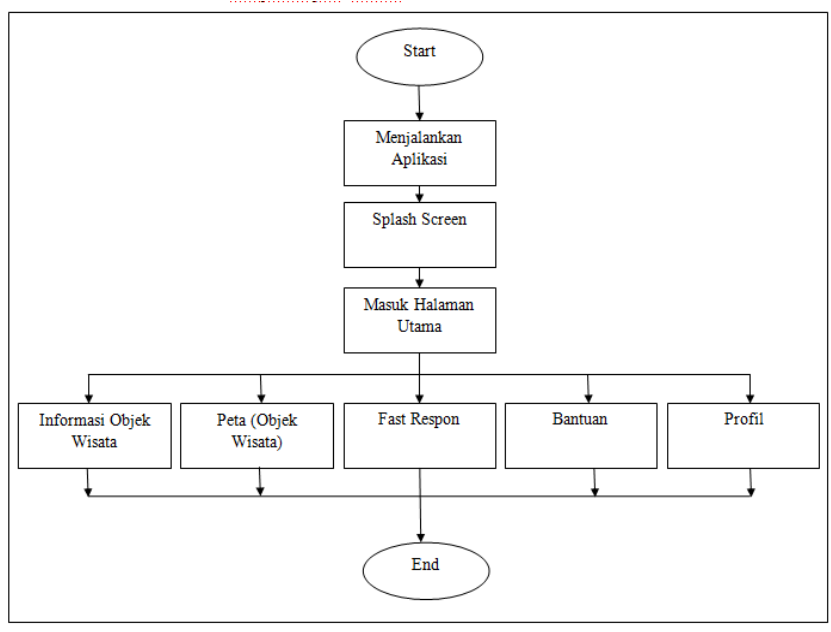

Gambar 3 Proses Bisnis Aplikasi User

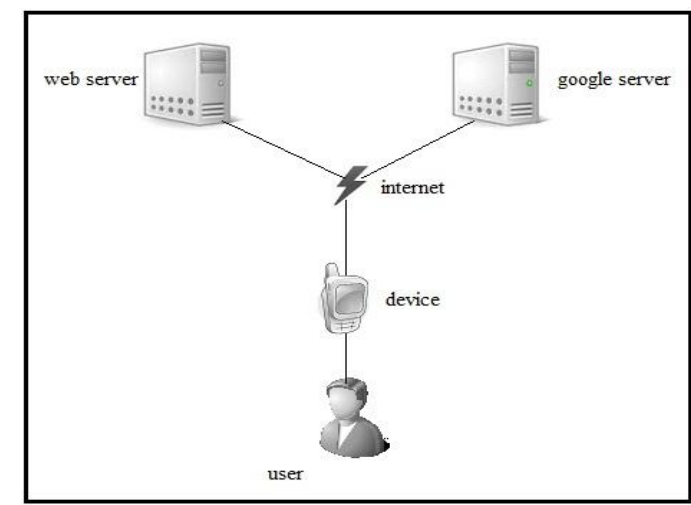

Gambar 4 Arsitektur Aplikasi

\section{Rancangan Arsitektur}

Pada aplikasi ini tidak hanya melibatkan perangkat mobile J2ME, tetapi juga berhubungan dengan server Google Maps yang menyediakan Google Maps API. Selain berhubungan dengan Google Maps server, aplikasi ini juga berhubungan dengan server khusus sebagai penyedia script yang akan dijalankan pada aplikasi ini. Pada aplikasi ini menggunakan perangkat mobile J2ME, menggunakan bahasa pemrograman java sebagai akses client dan bahasa PHP sebagai server. Arsitektur aplikasi ditunjukkan pada Gambar 4.

Alur dari arsitektur pada Gambar 4 adalah aplikasi J2ME melakukan request ke web server untuk mendapatkan hasil sesuai apa yang diinginkan oleh client. Setelah request ditanggapi oleh server, kemudian server akan menjalankan fungsi yang dimaksud untuk selanjutnya mengembalikan hasil sesuai dengan yang diminta oleh client pada perangkat mobile. Google Maps bertugas dalam menyediakan data peta (maps). Sedangkan perangkat mobile J2ME bertugas menampilkan data yang telah diolah oleh web server terhadap akses ke Google Maps yang akan menampilkan hasilnya dalam bentuk peta.

Use case diagram merepresentasikan sebuah interaksi antara aktor dengan sistem [9]. Salah satu manfaat dari use case adalah calon pengguna sistem dapat memperoleh pemahaman yang menyeluruh tentang sistem yang akan dirancang. Use case diagram sistem ditunjukkan pada Gambar 5. 


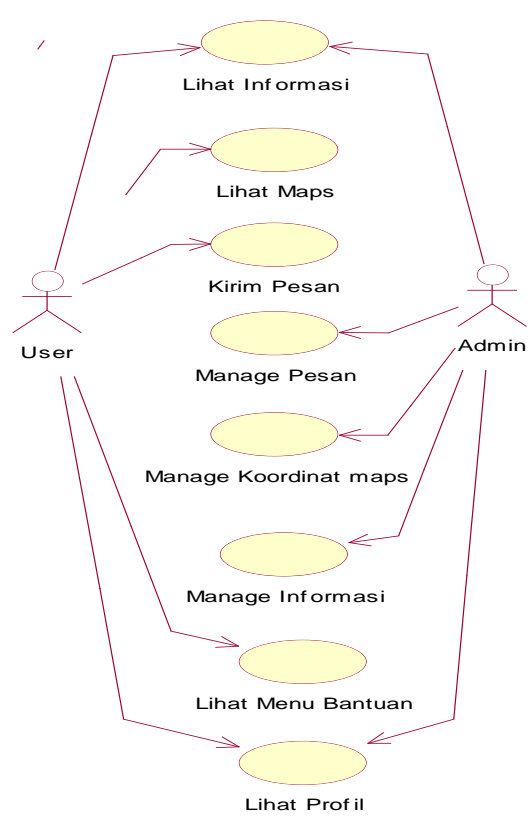

Gambar 5 Use Case Diagram Sistem

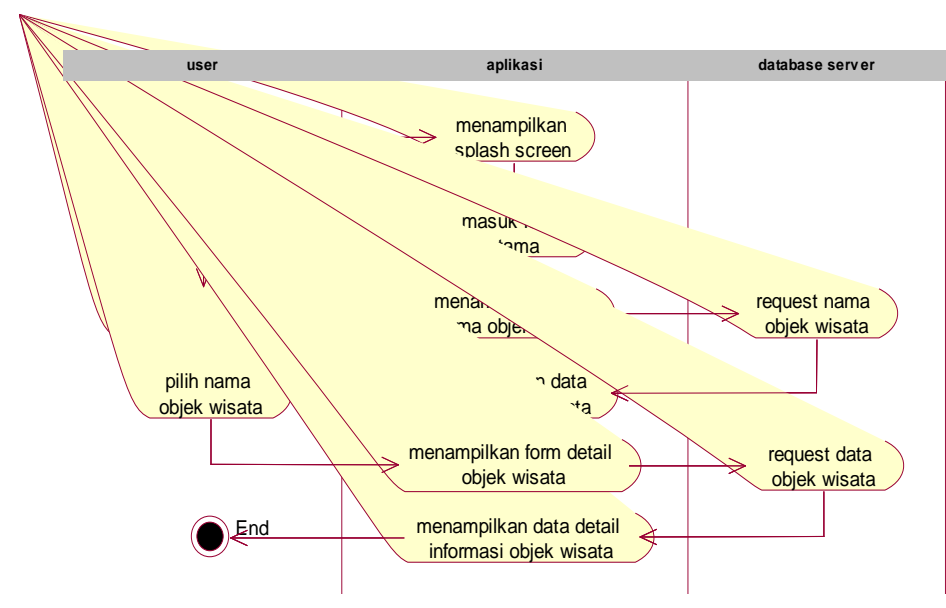

Gambar 6 Activity Diagram User Informasi Objek Wisata

Berdasarkan Gambar 5 dapat dijelaskan bahwa terdapat dua aktor yaitu admin dan user. Admin adalah orang yang memiliki otoritas dalam management data user, dimana Admin memiliki hak untuk melihat informasi objek wisata sekaligus melakukan pengaturan di dalamnya seperti insert, update, dan delete. Admin juga bisa melakukan pengaturan pada koordinat maps yang nantinya akan ditampilkan pada perangkat mobile user melalui menu Peta (Objek Wisata). Selain itu admin juga bisa melihat profil serta melakukan pengaturan pada respon atau pesan yang dikirimkan oleh user melalui perangkat mobile. Semua aktivitas admin dilakukan pada halaman web, dimana admin harus terlebih dahulu login agar bisa melakukan aktivitas tersebut.

Sedangkan User hanya bisa melihat Informasi Objek Wisata, Peta (Objek Wisata), mengirimkan respon atau pesan melalui menu Fast Respon, serta mampu melihat menu Bantuan dan Profil. Semua aktivitas user dilakukan pada perangkat mobile, dimana user harus terhubungkan dengan koneksi internet agar bisa mengakses semua informasi objek wisata yang dipilih pada aplikasi panduan pariwisata mobile ini.

Activity diagram merupakan salah satu cara untuk memodelkan event-event yang terjadi dalam usecase [9]. Gambar 6 menunjukkan Activity diagram user saat melihat informasi objek wisata. Gambar 7 menunjukkan Activity diagram user saat melihat maps atau peta. Gambar 8 menunjukkan Activity diagram user saat mengirimkan respon atau pesan kepada admin.

Gambar 6 menggambarkan aktifitas yang dilakukan oleh user saat user ingin me lihat detail informasi objek wisata yang ada di Kabupaten Semarang. Pertama yang dilakukan oleh user adalah menjalankan aplikasi mobile tersebut, kemudian akan muncul beberapa saat tampilan splash screen, setelah itu user akan masuk pada form utama. Pada form utama user memilih menu Informasi Objek Wisata, kemudian aplikasi akan mengirimkan request data objek wisata pada database berupa nama objek wisata, nama objek wisata untuk kemudian akan ditampilkan pada form aplikasi mobile. Berdasarkan nama objek wisata yang tampil, user dapat memilih objek wisata mana yang akan ditampilkan secara detail pada form aplikasi tersebut dengan mengirimkan request data objek wisata pada database berupa nama objek wisata, alamat, serta keterangan untuk kemudian akan ditampilkan. 


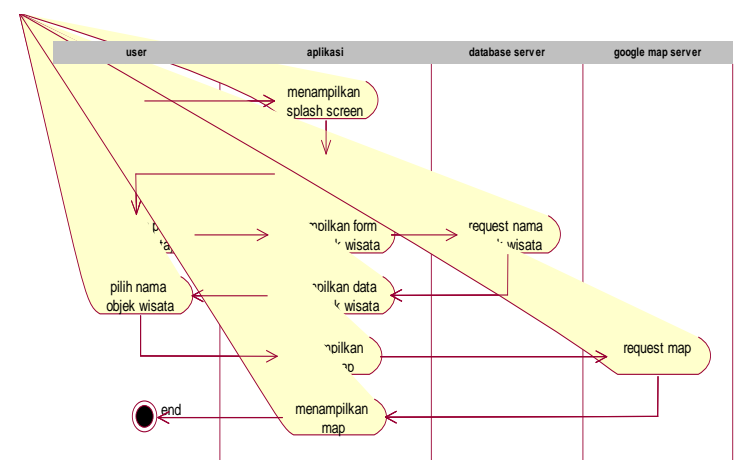

Gambar 7 Activity Diagram User Peta (Objek Wisata)

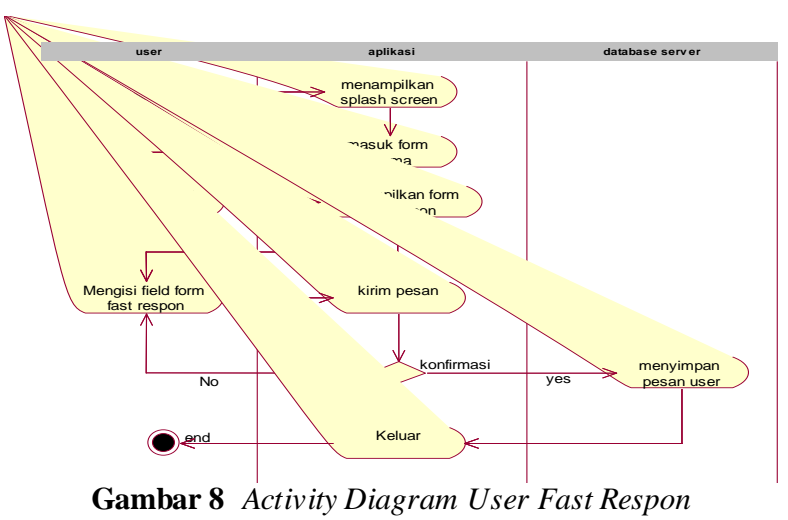

Gambar 8 Activity Diagram User Fast Respon

Gambar 7 menggambarkan aktifitas yang dilakukan oleh user saat user ingin melihat maps atau peta objek wisata yang ada di Kabupaten Semarang.

Gambar 8 menggambarkan aktifitas yang dilakukan oleh user saat user ingin meninggalkan pesan di aplikasi mobile kepada admin.

Sequence diagram merupakan interaction diagram yang memperlihatkan event-event yang berurutan sepanjang berjalannya waktu [9]. Gambar 9 menunjukkan sequence diagram admin dalam melakukan tambah data. Admin dapat menambah data objek wisata, dengan memasukkan data pada field nama objek wisata, lokasi objek wisata, koordinat, gambar, dan keterangan. Perintah kemudian dikirimkan ke TambahObjekUI dan diteruskan ke TambahObjekCon lalu kemudian ke Database, data baru tersimpan di Database untuk kemudian ditampilkan.

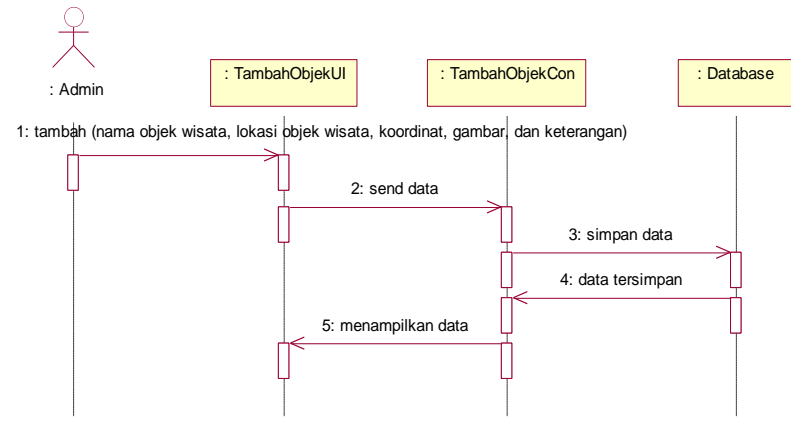

Gambar 9 Sequence Diagram Tambah Objek Wisata

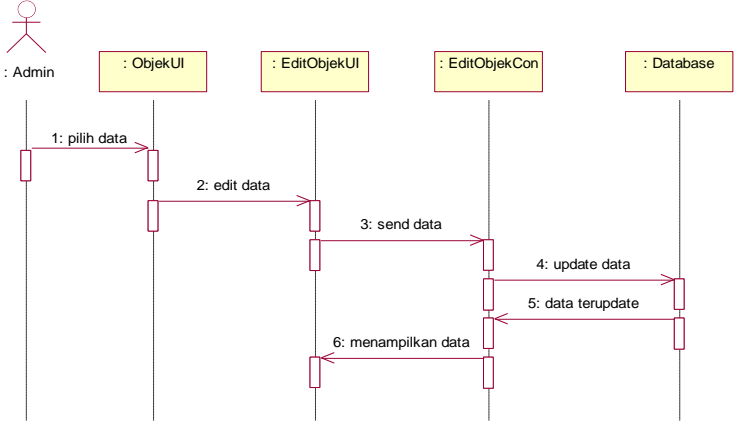

Gambar 10 Sequence Diagram Update Objek Wisata

Sequence diagram update data ditunjukkan pada Gambar 10 yang menjelaskan sequence diagram admin dalam melakukan edit data objek wisata. Pada ObjekUI atau halaman data jika admin ingin mengubah data objek wisata harus memilih objek wisata yang akan diedit terlebih dahulu. Perintah update data dikirim ke EditObjekUI, dan dilakukan update data. Kemudian diteruskan ke EditObjekCon lalu ke Database. Database mengembalikan permintaan dan mengkonfirmasikannya kepada admin .

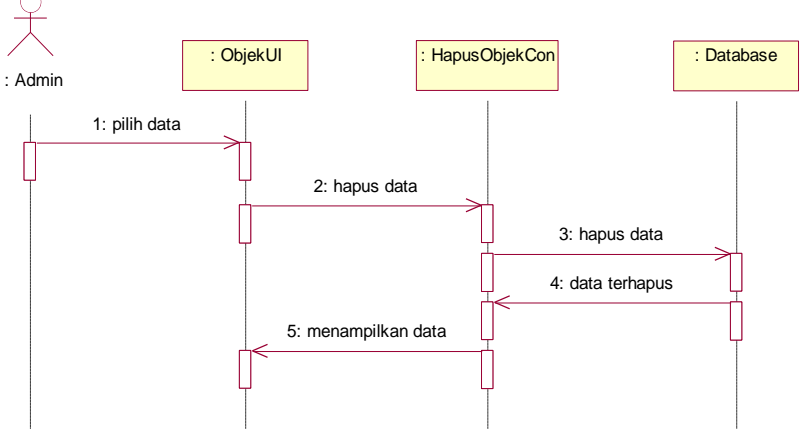

Gambar 11 Sequence Diagram Hapus Objek Wisata 
Gambar 11 menunjukkan tentang sequence diagram hapus objek wisata. Pada ObjekUI atau halaman data jika admin ingin menghapus objek wisata, sebelumnya harus memilih objek wisata yang akan dihapus. Perintah hapus data objek wisata diteruskan ke HapusObjekCon lalu ke Database, sehingga data terhapus dari Database.

\section{Hasil Dan Pembahas an}

Berdasarkan rancangan yang telah dipaparkan, dikembangkan sebuah aplikasi panduan pariwisata berbasis mobile yang terdiri dari aplikasi mobile itu sendiri sebagai client dengan menggunakan framework LWUIT dan aplikasi web sebagai server, dimana semua pengaturan informasi akan dilakukan di halaman web sedangkan pada aplikasi mobile hanya mengakses informasi yang ada pada halaman web tersebut.

\section{Aplikasi User}

\section{- Form Utama Aplikasi}

Form utama pada aplikasi panduan pariwisata mobile ini berisi menu pilihan yang terdiri dari menu Informasi Objek Wisata, Peta (Objek Wisata), Fast Respon, Bantuan, dan Profil. Menu yang disediakan tampil dalam bentuk list bergambar. Gambar 12 menunjukkan form utama aplikasi panduan pariw isata mobile.

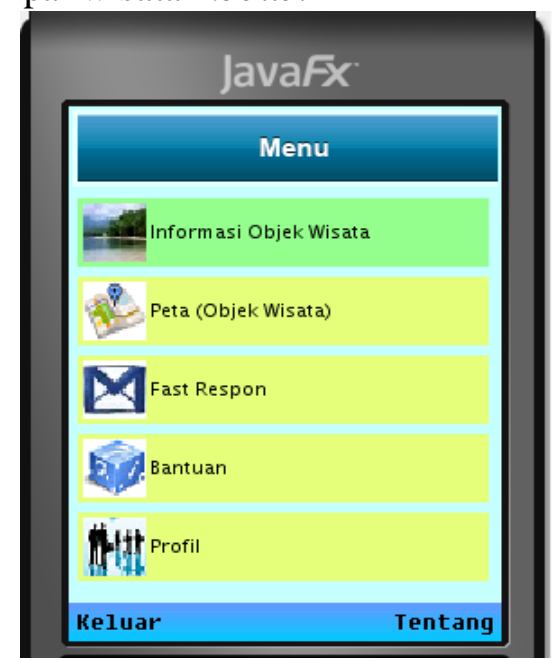

Gambar 12 Form Utama Aplikasi Panduan Pariwisata Mobile

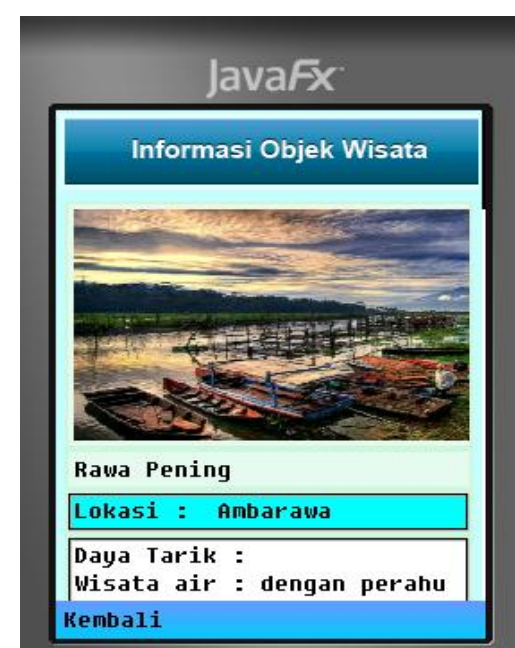

Gambar 13 Form Informasi Objek Wisata

\section{- Form Informasi Objek Wis ata}

Form Informasi Objek Wisata berisi data informasi apa saja yang bisa di akses oleh user dalam aplikasi panduan pariw isata mobile ini. Di dalam form informasi objek wisata ini di sajikan informasi seperti nama objek wisata, gambar objek wisata, dan deskripsi mengenai objek wisata tersebut. Gambar 13 menunjukkan form informasi objek wisata.

\section{- Form Peta (Objek Wis ata)}

Form Peta (Objek Wisata) berisi gambar peta atau maps di mana user dapat melihat lokasi objek wisata yang dipilih tersebut berada. Maps yang ditampilkan pada aplikasi mobile ini diakses menggunakan implementasi dari teknologi google maps. Gambar 14 menunjukkan form peta (objek wisata). 


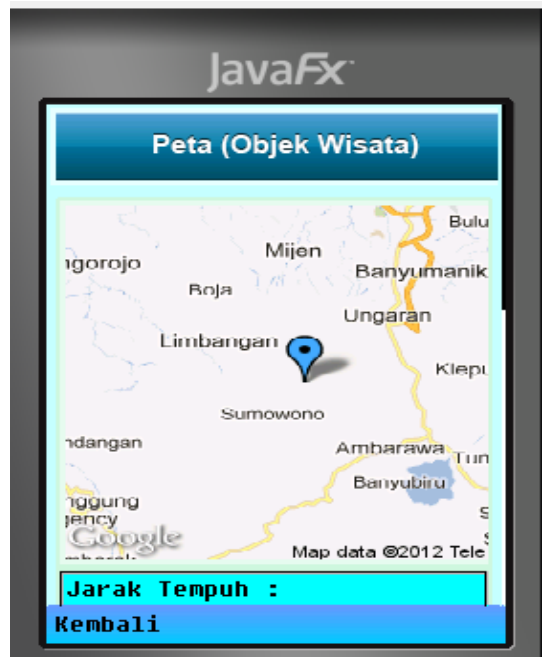

Gambar 14 Form Peta (Objek Wisata)

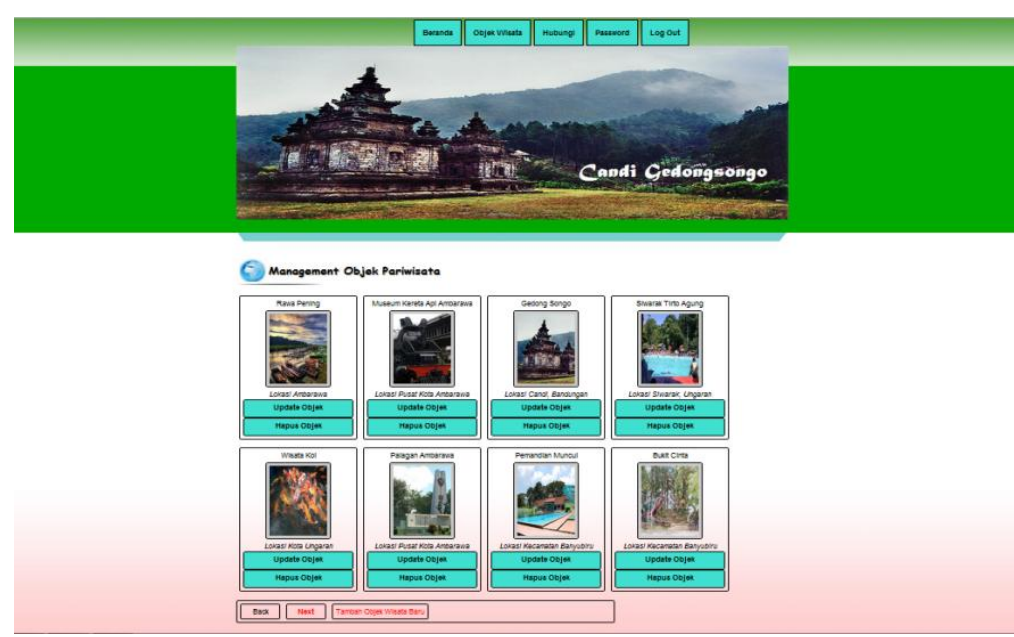

Gambar 15 Halaman Management Objek Pariwisata

\section{Aplikasi Web Admin}

\section{- Halaman Data Management Objek Pariwis ata}

Halaman Management Objek Pariwisata menampilkan data yang berkaitan dengan informasi objek wisata yang telah di upload oleh admin. Pada halaman ini seorang admin mampu melakukan aktivitas seperti tambah objek wisata, edit objek wisata, dan hapus objek wisata. Gambar 15 menunjukkan halaman Management Objek Pariwisata.

\section{Pengujian Sistem}

Pengujian ini berfungsi untuk melihat sejauh mana aplikasi ini dapat berjalan dan untuk menemukan kesalahan yang mungkin terjadi. Pengujian aplikasi ini terdiri dari dua teknik pengujian, yaitu:

\section{- $\quad$ Pengujian Alfa}

Pengujian Alfa merupakan pengujian aplikasi yang dilakukan oleh pembuat ataupun orangorang yang terlibat di dalamnya [10]. Tujuan dari pengujian aplikasi ini adalah untuk mengetahui apakah aplikasi yang telah dibuat berjalan pada perangkat mobile, data yang ada pada web server apakah bisa diakses oleh aplikasi yang ada di perangkat mobile baik itu berupa gambar, keterangan, ataupun maps yang langsung diakses dari server google maps, serta untuk mengetahui apakah respon yang dilakukan oleh user bisa langsung tersimpan di database dan tampil di halaman web admin. Semua pengujian tersebut dilakukan dengan evaluasi prototyping.

\section{a. Evaluasi Tahap Pertama}

- Pengujian pertama dilakukan dengan menjalankan Aplikasi Panduan Pariwisata pada perangkat mobile yang sudah terinstal di Nokia Asha 303, Pada pengujian ini, web server belum di upload di internet dengan menggunakan web hosting, sehingga otomatis semua menu yang membutuhkan koneksi internet belum bisa diakses. Pengujian hanya berfokus pada tampilan dan pergerakan form. Dari pengujian tersebut terlihat bahwa form fast respon tidak berjalan dengan sempurna sehingga transisition nya berjalan pelan tidak seperti transisition pada form yang lain.

- Pengujian kedua dilakukan dengan menjalankan web yang sudah di upload di internet menggunakan free web hosting http://www.byethost.com. Pada pengujian ini semua file sukses di upload dan mampu dijalankan pada web browser yang terkoneksi internet dengan baik.

- Pengujian ketiga dilakukan dengan menja lankan kembali aplikasi mobile pada emulator setelah melakukan update URL pada class di netbeans dimana aplikasi mobile ini dibangun, yang sebelumnya menggunakan server localhost menjadi ekodili.byethost7.com. Pengujian ini masih dilakukan pada tahap emulator hanya untuk mengetahui apakah data yang ada pada internet bisa diakses oleh aplikasi mobile yang dijalankan melalui emulator atau tidak. Hasil dari pengujian ini menunjukkan bahwa semua data yang ada di web internet bisa diakses oleh emulator. 
- Pengujian keempat dilakukan kembali dengan menjalankan Aplikasi Panduan Pariwisata pada perangkat mobile yang sudah terinstal di Nokia Asha 303. Pada pengujian ini, menu Informasi Objek Wisata dan Peta (Objek Wisata) dimana sebelumnya semua data bisa diakses oleh emulator, kali ini tidak bisa diakses oleh perangkat mobile Nokia Asha 303. Sedangkan menu lainnya bisa berjalan dengan baik.

Sebagai hasil dari evaluasi terhadap prototype, aplikasi diperbaiki dengan perubahan sebagai berikut.

- Mengubah struktur penyusunan form pada menu fast respon dimana sebelumnya semua komponen di susun di dalam container terlebih dahulu sebelum ditampilkan di form, kali ini semua komponen langsung disusun pada form sehingga tidak terjadi penumpukan form pada menu fast respon.

- Melakukan pengecekan apakah ada code yang terlewat pada class yang berkaitan dengan menu informasi objek wisata dan peta (objek wisata) terhadap pengaturan koneksi dimana sebelumnya tidak bisa melakukan akses data terhadap web server di internet pada perangkat mobile. Pada pengecekan ini ternyata ditemukan bahwa String URL pada masing-masing class yang berkaitan dengan menu informasi objek wisata dan peta (objek wisata) belum diganti dengan URL server di web hosting dan masih menggunakan URL server local.

\section{b. Evaluasi Tahap Kedua}

Setelah perbaikan dan perubahan yang telah dilakukan pada evaluasi tahap pertama, maka pada tahap kedua ini dilakukan kembali evaluasi terhadap Aplikasi Panduan Pariwisata pada perangkat mobile.

Pada evaluasi tahap kedua ini tidak ditemukan kesalahan baik pada web server di internet maupun aplikasi yang terdapat pada perangkat mobile. Kali ini koneksi dari kedua aplikasi tersebut, aplikasi web dan aplikasi mobile mampu melakukan akses data dengan baik termasuk jika user mengirimkan pesan melalui menu form fast respon, maka tidak ada kendala lagi mengenai pergerakan form yang pelan serta data bisa langsung masuk pada database dan tampil di halaman web admin.

\section{Pengujian Beta}

Pengujian beta dilakukan oleh pengguna aplikasi, yaitu pihak Dinas Pemuda, Olahraga, Kebudayaan, dan Pariwisata Kabupaten Semarang sebagai admin, dan pengguna atau user. Tujuan dari pengujian ini adalah untuk mengetahui apakah aplikasi ini sudah membantu dalam memberikan informasi kepada pengguna serta mendukung sebagai media promosi atau tidak. Pengujian dilakukan dengan membagikan kuesioner yang diberikan kepada 32 responden yaitu terdiri 3 orang responden dari pihak Dinas Pemuda, Olahraga, Kebudayaan, dan Pariwisata Kabupaten Semarang serta 29 orang responden yang dilakukan secara acak. Pada lembar kuesioner terdapat lima pertanyaan. Berdasarkan hasil analis is kuesioner, dapat disimpulkan sebanyak 71.88\% menjawab bahwa aplikasi ini sangat mudah digunakan, 59.38\% menjawab bahwa visualisasi data pada aplikasi ini sangat mudah dipahami, 65.36\% menjawab bahwa desain tampilan aplikasi ini menarik, $50.00 \%$ menjawab bahwa aplikasi membantu Disporabudpar Kabupaten Semarang dalam promosi terhadap objek wisata yang ada di Kabupaten Semarang, dan 78.13\% menjawab bahwa aplikasi ini sangat membantu calon wisatawan untuk mendapatkan informasi mengenai objek wisata yang ada di Kabupaten Semarang.

\section{Analisis Sistem}

Penggunaan framework LWUIT pada aplikasi panduan pariwisata mobile menjadikan desain tampilan menu semakin mudah dipahami dan lebih menarik dengan adanya efek transisition sehingga mampu menarik perhatian user untuk segera menjalankan aplikasi tersebut. Sedangkan dalam melakukan akses data pada aplikasi panduan pariwisata mobile ini bersifat dinamis karena dibangun dengan melibatkan server. Agar bisa mendapatkan informasi yang dibutuhkan berkaitan dengan objek wisata yang ada di Kabupaten Semarang maka dibutuhkan koneksi internet untuk menjalankannya dengan biaya yang dibutuhkan dalam mengakses aplikasi panduan pariwisata mobile ini tergantung pada provider jaringan masing-masing perangkat mobile yang digunakan. 


\section{Kesimpulan}

Berdasarkan penelitian dan pembahasan yang telah dilakukan terhadap penerapan framework LWUIT pada J2ME dalam aplikasi panduan pariwisata mobile di Kabupaten Semarang maka kesimpulan yang dapat diambil adalah bahwa penggunaan framework LWUIT pada J2ME di aplikasi ini menjadi lebih menarik dan mudah dalam proses develope. Aplikasi ini juga mampu membantu pihak Dinas Pemuda, Olahraga, Kebudayaan, dan Pariwisata Kabupaten Semarang guna melakukan promosi terhadap objek wisata yang ada serta membantu juga para calon wisatawan dalam mendapatkan informasi mengenai objek wisata di kabupaten Semarang. Dengan adanya web server maka informasi pada aplikasi ini akan mengikuti perubahan yang ada pada halaman web, sehingga informasi yang didapatkan oleh user selalu up to date.

\section{Daftar Pus taka/Pustaka Acuan}

[1] Nielsen Charts Asia's Mobile Advertising Ecosystem, http://www.asiamediajournal.com/pressrelease.php?id=3756. Diakses tanggal 6 September 2012.

[2] Dedy Indrawan, Entin Martiana K, Kholid Fathoni, 2010. Game Ilmu Pengetahuan untuk Usia Tiga sampai Tujuh Tahun Berbasis J2ME. Surabaya : Institut Teknologi Sepuluh Nopember.

[3] Farida, Intan Nur, 2010. Aplikasi Bergerak (Mobile Application) Pemandu Wisata Wilayah Malang Raya Berbasis J2ME. Malang : Universitas Islam Negri (UIN) Maula na Malik I brahim.

[4] Satria Candra Wibawa, Yuliana Setiowati, Kholid Fathoni, 2010. Aplikasi Gitar Player Menggunakan Teknologi Java Mobile (J2ME). Surabaya : Institut Teknologi Sepuluh Nopember.

[5] Kodrat IS, Moh. Firomas AN, Adian FR, 2011. Aplikasi Email Client Pada Ponsel untuk Memproses Informasi Perkuliahan. Semarang : Universitas Diponegoro.

[6] Jeremia, 2012. Percobaan LWUIT, Framework Anti, Fragmentasi Buat J2ME. http://jlh40.wordpress.com/201 1/04/13/percobaan-lwuit-framework-anti-fragmentasi-buatj2me/. Diakses tanggal 6 September 2012.

[7] Eva paramitha Widyanto, 2007. Perancangan Buku Panduan Wisata Kota lama di Semarang. Surabaya : Universitas Kristen Petra

[8] Pressman, Roger.S. 2001. Software Engineering : A Practioner's Approach. 4th, Boston: McGrawHill

[9] Nugroho, Adi. 2005. Rational Rose Untuk Pemodelan Berorientasi Objek. Bandung: Informatika.

[10] Vaughan, Tay. 2004. Multimedia: Making It Work, Edisi 6. Yogyakarta: ANDI. 